Article

\title{
Teaching a Foreign Language Using Videos
}

\author{
Veronika Pisarenko
}

Department of Foreign Languages, Institute of Management in Economic, Environmental and Social Systems of Southern Federal University, 22, Chekhov Str., Taganrog 347922, Russia; pisarenko@sfedu.ru; Tel.: +7-9-281-386-615

Received: 23 August 2017; Accepted: 6 October 2017; Published: 17 October 2017

\begin{abstract}
Education technology represents a system of influences on the trainee in the training process. It involves the management of a didactic process with the inclusion of stages of the trainees' activities, organization and control. The problem of educational technology efficiency is based on strategies of representation, acquisition, storing, reproducing, and actualization of various forms of educational information. This paper considers audiovisual technologies (AT) for foreign language training in high school. It reports on a number of audiovisual activities in foreign language training. The research provides some ideas of the students' perception of video in the education process. The classification of video materials allows consideration of the different pedagogical and didactic conditions of AT realization. The functional features of a video film in the training process and four stages of audiovisual education technology based on a video film are described. To present the process of training, the pedagogical algorithms based on the structure of the knowledge acquisition process are developed according to the aims of viewing (illustrative viewing, fact-finding, studying, critical, and search viewing. The stages of AT realization (previewing, presentation, after-viewing, and actualization) are considered. An educational intervention using AT is developed and we investigate (1) the effectiveness of audiovisual technology as a teaching method; and (2) the degree of knowledge acquisition of the language content proposed to students. The aim of foreign language training is to form and to develop foreign language communicative competence that includes different skills, abilities and knowledge of grammar, pronunciation and vocabulary, skills in reading, writing, audition and speaking. To estimate the communicative competence level, we used the calculation of knowledge acquisition factor of training material. A significant improvement was observed in the acquired knowledge of a foreign language and AT were perceived to be effective in teaching foreign languages. AT were perceived to facilitate students' knowledge acquisition and stimulate active learning. Foreign language training based on AT positively influences students' performance and should play a leading role in the effective communicative competence formation and development.
\end{abstract}

Keywords: audiovisual technologies; foreign language teaching; higher education; pedagogics; pedagogical algorithms; techniques of teaching; technologies of education; video resources

\section{Introduction}

The problem of educational technology efficiency is connected to the problem of strategies of representation, acquisition, storing and reproduction of various forms of educational information. The problem of a human and information interaction in the educational process is connected to the problem of efficiency of modern educational technologies. Formalizing pedagogical activities' education technology allows reproduction of the successful experience of teachers. Education technology represents a special way of interacting with educational information.

This question has been widely discussed in literature. Various aspects of the methodology of knowledge transfer in educational systems have been studied by scientists in different contexts. There are a great number of papers and books concerning the knowledge transfer problem. V.I. Vernadsky's 
ideas have the greatest value in the era of integration of the huge volume of knowledge collected by humanity (Vernadsky 1998). Now the integration processes predicted by V.I. Vernadsky has become a reality. They become a basis of the fourth scientific revolution (Kuhn 1996; Stepin 2007, 2008, 2009). Moreover, their further advancement in all its spheres, in particular, in the education sphere, is not only actual, but also natural. Therefore, in the sphere of the trinity approach in education (Kibalchenko et al. 2015; Kibalchenko and Valentinovna 2016; Kibalchenko and Zabalueva 2017) the expediency of use of natural interaction processes in informative experience cognitive structures has been shown (text-image-sense; rational—sensual-intuitive, etc.). The research of this interaction gives the chance to reveal additional reserves of well-known educational strategies and technologies (Babansky 1973, 1987; Deetman 1989; Zankov 1963, 1964; Vygotsky 1977; Vygotsky et al. 1979; Zaporozhets and Elkonin 1973).

One of the major requirements of any activity's efficiency is the creation of comfortable psychological conditions for it (Carterette and Friedman 1978). Visualization plays an important role in this process. Meanwhile in modern educational activity the attention of teachers to the figurative-emotional sphere of trainees is not sufficient. The idea of passing from explanatory and illustrative pedagogics to a structurally new direction in the training theory serves as stimulus for visualization introduction in educational process (Bégin 2008; Parker 1979). The introduction of visualization results in the creation of the educational environment that is considered to be more comfortable psychologically and safe for the trainee (Pisarenko and Bondarev 2016). Thereupon, the problem of humanitarian subjects teaching modernization can be solved by means of the creation of a simple, reliable and effective model of interaction between a teacher, trainees, a studied theme and subjects. For this problem realization, there was consideration of a complex of didactic means that represents a system in which visual means are included. It helps to generalize and remember the studied material promoting its longer preservation in memory and easy reproduction (Alava and Christiane 1999; Andrade and Spinillo 2013; Friedrich 2001; Wolfs 2007).

There are many definitions and concepts of technology in literature. Education technology is a system of influences on the learner in the learning process (Arsaliev 2015, 2016). It involves the management of the didactic process with the inclusion of stages of organization and control of the activities of a trainee. Technology is a theoretical pedagogical project of educational activity management. One of the key elements of any education technology is feedback between the result and the transitional states of the education process. Educational technology of organization of educational and cognitive activity aims at managing the process of solving training tasks.

It should be recognized that in educational practice the teacher has to use the data regarding the level of educational and cognitive activity of students; to consider their individual way of learning; to provide variability of the educational process; to create for each student an information environment and to use didactic resources adequate to his stylistic peculiarities and the level of knowledge.

The process of planning, organization, coordination and monitoring of learning outcomes represents the main activity for the teacher when developing new education technologies. We are sure that to solve existing and emerging problems in the design and organization of the educational process (learning), we have to use new, effective approaches and methods to improve the quality of functioning for a complete system of education (Deetman 1989). The necessity of a unified multidisciplinary approach to the solution of pedagogical problems and challenges is obvious.

Education technology as a process has the following structure represented in Figure 1: 


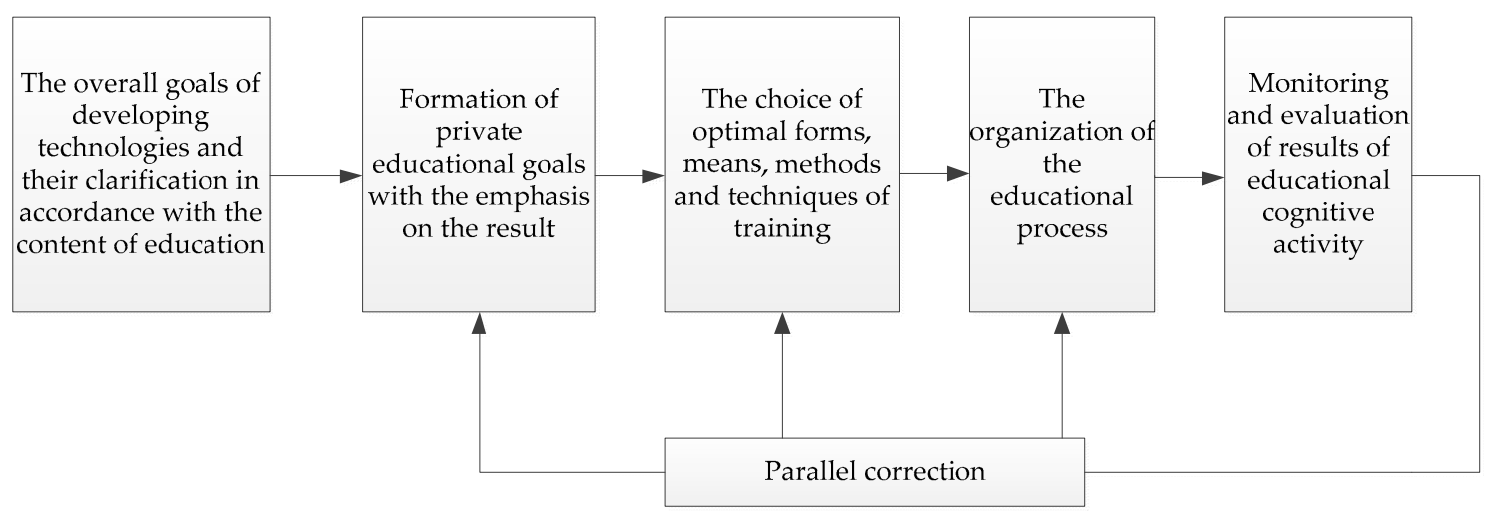

Figure 1. The scheme of educational technology as a process.

In this paper, we will focus on audiovisual technology that is very popular and commonly used in teaching foreign languages. Audiovisual Technology (AT) represents a new approach to teaching methods and techniques and this is the current reality in education. Audiovisual materials are very popular in teaching and training but their application is sometimes random and arbitrary. AT improves the efficiency and availability of teaching resources.

AT is a term for the abstraction of the process of constructing a set of operations, methods and techniques based on video resources and resulting in competence formation (Pisarenko 2015). This technology is based on use of human audio and visual channels of information perception. It permits organization of perception in maximal value. This is very important for teaching foreign languages. Video resources allow the demonstration of the object of studies-a foreign language-in real conditions (Pisarenko and Krasnoshchekova 2016). Video permits demonstration of not only a language but also the whole environment where it exists, including cultural, social, ethnic, historical and many other aspects (Pisarenko and Arsaliev 2016).

\section{Materials and Methods}

The ideas of our work are based on an interdisciplinary approach (Baguley et al. 2013; Kitto and Bernard 2002; Soriano 1995) that focuses on the integration of knowledge and achievements of different sciences. The basic methodological ideas and synergistic approaches promoted integrated knowledge of the control laws, theoretical synthesis of the optimal models of technologization of pedagogical leadership and cognitive processes. Audiovisual technologies are based on systemic, synergetic, personality-oriented, integrated and technological approaches. A systematic approach means considering audiovisual technologies as systems of actions, a student's personality as a system of components of personality sphere etc. (Stepin 2008). A synergetic approach allows the consideration of the education process as nonlinear and self-developing (Pisarenko 2015). Personal orientation of audiovisual technology means that the teacher has to take into account students' individual characteristics (Pisarenko and Bondarev 2016). The integrated approach allows presentation of audiovisual technology as an integration of studying and teaching forms, activities, methods, tutorials, forms of educational information content and representation (Pisarenko and Bondarev 2016). The technological approach means the representation of an educational process as a sequence of pedagogical operations defined by education process logic.

\subsection{Classification of Audiovisual Materials in Training a Foreign Language}

We consider any material that is demonstrated in the educational process with use of video equipment as a video material (a video fragment, a video course, a video program, a video film, a video clip etc.). The use of video materials in an educational process is carried out by means of audiovisual technologies of training. 
To consider the problem of audiovisual technologies in foreign language training it is necessary to recognize that we classify all audiovisual materials for foreign language teaching as: (1) video courses; (2) video films; and (3) all other video information.

\subsection{Video Courses and Video Films}

Video courses. A video course represents a single whole including the tasks and educational problems, created by authors of the video course. The teacher has to follow the structure of educational processes offered by the authors of a video course. A video course is a developed technology aimed at realization of certain goals.

Video films. Use of video films promotes realization of the requirement of a communicative technique to present the process of language-mastering by comprehension of live culture speaking another language; an individualization of training and development of motivation of speech activity of students (Pisarenko 2015; Pisarenko and Arsaliev 2016; Pisarenko and Krasnoshchekova 2016).

Another advantage of video films is their emotional influence on students. Therefore, special attention should be given to the process of formation of the personal relation to the materials used in training process. It is the main objective of the personality focused training paradigm. Successful achievement of this purpose is possible firstly at regular display of video films, and secondly, at their methodically organized demonstration. The use of video films helps to develop various kinds of student's activity, and also their attention and memory. At video material viewing, there is an atmosphere of joint informative activity in audience that promotes the increasing in attention concentration. Use of various channels of the information perception influences positively durability of storing of a regional geographic and language material (Rieber and Robinson 2004). Psychological features of video films influence on students promote an intensification of educational process and create favorable conditions for the communicative competence formation. The teacher defines, whether it is necessary to include a video film consistently in educational process, or to use separate episodes taking into account conformity of subjects of a video film to a basic word stock and the communicative situations included in the foreign language program for a concrete grade level. The information quantity and character should correspond to quantity and quality of the information, which the student studying a foreign language is capable to acquire at a given time.

Efficiency of use of a video film in educational process depends on exact definition of its position in training system, on coordination of educational possibilities of a video film with training problems, on rationality of organization of work, and on functional features of a video film.

There are the following functional features of a video film used in educational process:

- Informative and training function - the student is involved in the film's subject line and in the process of information transfer simultaneously; this information will be used in the course of training;

- Illustrative and evident function - video film shows a subject line in the art form;

- Organizational and operational - it is realized in concentration and the subsequent management of students' attention by means of a subject line and art features of its embodiment;

- Educational-it is embodied in realization of certain ideas in the art form and statement of problems which the student will discuss further;

- Integrating - in the course of viewing there is a process of integration of various kinds of perceptions, and also various aspects of language-phonetic, lexical etc. (Pisarenko and Krasnoshchekova 2016).

There are the following four stages in the audiovisual technology structure with use of video films (Pisarenko and Krasnoshchekova 2016):

1. Preliminary work - preliminary removal of language and cultural difficulties, statement of an educational task;

2. Perception-development of skills of the information perception; 
3. Control of understanding of the basic maintenance;

4. Development of language skills and abilities of oral speech.

Preliminary work. The students are informed about the name of a film and they are offered to come out with assumptions of film's maintenance, time and a scene of action, possible characters. Phrases for assumption expression are introduced and trained necessarily. Then the new lexical material that is necessary for understanding of the maintenance of a film is introduced and intended for active possession. Introduction of new lexicon precedes demonstration of each part of a film. The special attention is given to phraseological units. The regional geographic comment is given necessarily.

Perception of a video film (in parts). Before viewing of each part, students can be offered questions that are necessary to be answered after viewing.

Control of understanding of the basic maintenance. In the beginning, students answer the questions offered by the teacher before viewing. Then the following educational tasks are proposed to students: Choose the right answer from the offered ones. Arrange the phrases according to the film plot. Break the film into logic parts and choose a heading for each of them of the offered ones. Associate the following statements (remarks) with the film heroes. Associate the following events with a place of action. Name participants of the following dialogues. Choose one correct variant of the phrase continuation etc.

Development of oral speech skills and abilities. It is possible to stimulate communicative activity by means of various tasks. It is necessary to begin with usual discussion of dynamics of a plot, features of heroes' appearances, characters and actions. The following types of tasks can be used: Describe the place and action time. Remember the names of the main characters of the film. Describe the appearance of the main characters of the film. Express your opinion on characters of heroes of the video film. Restore the chronology of the film events. Share your general impressions about the film. State the problems that were brought up by the authors of the film.

Further, we pass to the problem discussion. The teacher has to stimulate the students' oral statements not only about the film maintenance, but also about the problems and the ideas given by the film. The following types of questions and tasks can provide the discussion: How will you characterize the action time? What do you know about the scene of action? What associations do the given scene of action cause? What emotions do heroes of a film cause? Why? Whose character from heroes of the film is closest to yours? If you were on the place of the film heroes what would you do in this situation? Predict the further succession of events. Which problem do you consider as the most important one? If you were the film director, how would you illustrate a similar problem in your film?

For the decision of each tasks students should know not only the general maintenance of a video film, but also remember the details, and also be able to estimate events, to give the characteristic to characters, using words and expressions from speech support of a video film.

\subsection{All Other Video Information}

Practical experience shows that video films in a foreign language often represent difficulty for students of technical specialties because of great volume of a language and speech material (Corbalan et al. 2011). Video courses do not allow the teacher to vary the language training process. They are intended primarily for independent study of a foreign language. As the practice shows, it is much more effective to use separate video information (Pisarenko 2015; Pisarenko and Arsaliev 2016; Pisarenko and Krasnoshchekova 2016). Technologies of their use will differ from ones considered above.

In our opinion, the most productive video for the efficient organization of the educational process in a technical University is all other video information introduced in different forms: video programs, video clips, video fragments, video episode, video scene etc. Any sequence of actions, places, operations, events, with or without participation of people, animals, and techniques will give a subject for discussion, illustrate some phenomena, explain some idea etc. 


\subsection{Pedagogical Algorithms of Audiovisual Technologies Realization}

For realization of audiovisual technology of foreign language, training with use of video information it was suggested to use a pedagogical algorithm. Algorithmization represents the process of working out and realization of algorithms for the trainee. An algorithm in pedagogics represents a sequence of educational operations leading to the object in view. Algorithmization of educational process on a foreign language is of great importance, in particular, in case of tutorials use. It is necessary to notice that application of tutorials for foreign language training represents a well developed problem in a teaching technique. Nevertheless, occurrence of new tutorials (video, computers) demands working out of a special technique of work with them, allowing to use them most effectively and to receive a good level of results (Pisarenko 2015).

When video materials are being used in the training process, their demonstration has to be subordinated to the certain educational purposes and, hence, it has to be organized in a special way. The expediency of use of video in educational process is provided by the following facts: (1) availability of video information that can be recorded from various sources; (2) presence of a certain experience of using video equipment and a video production; (3) possibility of more active creative activity of the teacher. The following scheme of knowledge mastering process presented on Figure 2 has been used for the construction of algorithms of the foreign language training by means of video materials (Pisarenko 2015).

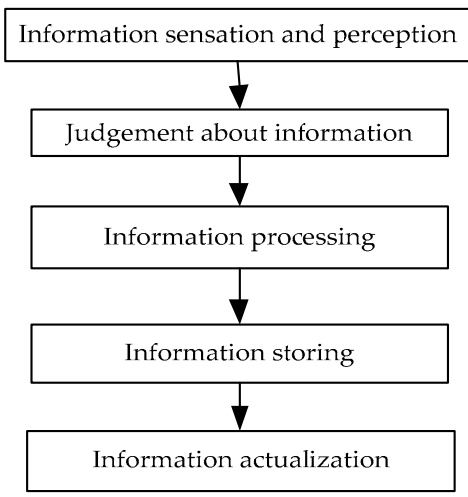

Figure 2. The scheme of knowledge mastering process when studying foreign language.

The scheme presented on Figure 3 reflects the specificity of process of foreign language training with use of audiovisual technologies. The work is organized as Figure 3 shows (Pisarenko 2015).

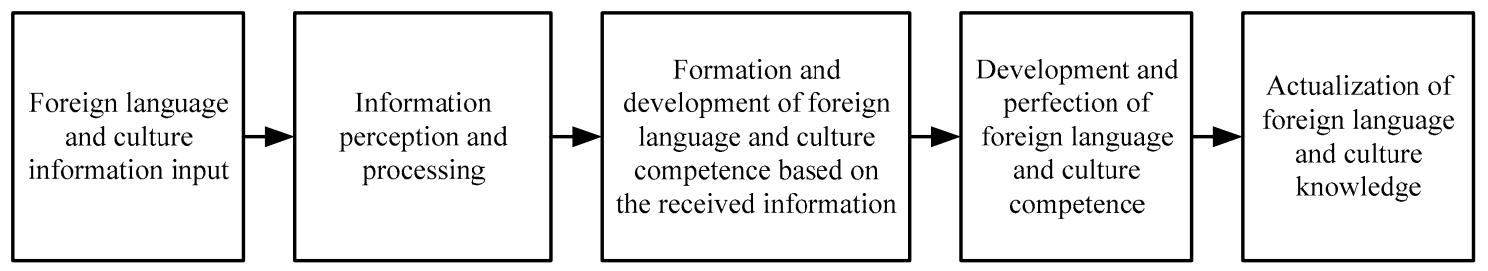

Figure 3. The general scheme of stages of work with video information at realization of audiovisual technologies for foreign language training.

On the basis of theoretical positions and the analysis of practical experience of video information use in educational process the pedagogical algorithm of video materials use for training foreign language has been developed according to the stages presented in Figure 4. 


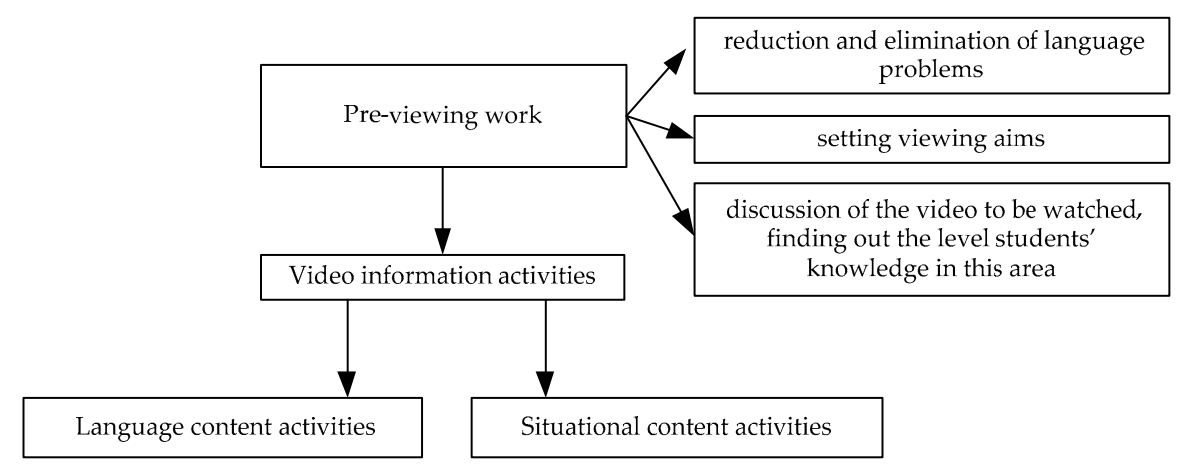

Figure 4. The main stages of educational process based on audiovisual technologies.

In realization of audiovisual technology based on video information, it is necessary to distinguish the following stages: previewing - statement of the purpose of viewing, the formulation of tasks, removal of lexical and grammatical difficulties; video information presentation-primary viewing; viewing repetition if necessary; after-viewing including: the control of understanding having various purposes and forms; formation, development and perfection of the foreign language communicative competence on the basis of lexical, grammatical and cultural video information maintenances; total control; actualization of the foreign language communicative competence as a result of work with video information.

The previewing stage has some variants of realization:

- The formulation of the global purpose of work and a specific goal of viewing and statement of an educational problem - what exactly should be made by students during presentation of a video information and after it?

- The formulation of the global purpose of work and a specific goal of viewing and statement of an educational problem, removal of lexical and grammatical difficulties, linguistic and cultural comments to a video information, having for an object the removal of difficulties of social and cultural character.

- Removal of difficulties assumes introduction of a new lexical and grammatical material, its training based on exercises, and the linguistic and cultural comment of the social and cultural phenomena that will appear in the course of viewing.

Video information presentation can be carried out one or many times. It depends on the viewing purpose. Besides, the presentation of video material can be realized in the form of the developed or fragmentary exposition. Developed exposition represents the complete video information having a subject basis; fragmentary exposition contains separate fragments, situations.

The after-viewing stage is the process of studying following a video information perception. First of all, this is the control having various purposes and forms. Control can be carried out in various forms: oral, written, face-to-face, individual, question-answer; in different volume-control of the plot understanding, control of perception and discussion of separate details of a plot. Control can be intermediate and total. The after-viewing stage is aimed at formation, development and perfection of a foreign language communicative competence on the basis of lexical, grammatical and cultural video information maintenances. This is a question of introduction, training and fastening language, speech and cultural material on the basis of the decision of various educational problems.

Actualization of a foreign language communicative competence represents a result of work with video information. It represents actually a stage of realization of the global purposes of work with video information. Actualization stage continues during all further use of a foreign language by the student. Frameworks of this process seem hard to be defined exactly. Nevertheless, we consider this stage should be necessarily allocated.

If we consider all stages of work with video information mentioned above, a variety of the training purposes, viewing types, specificity of the subject "Foreign language", it is possible to offer a number 
of operations sequences. They can be presented as algorithms of work with video materials that we suggest to use in foreign language training.

Illustrative viewing is aimed at the reception of evident illustrations for any language material, for example, the grammatical phenomena, the pronunciation skills, social and cultural phenomena. For example, we can use teaching material containing regional geographic information, the basic sights of any city of the studied language country. The grammatical phenomenon studied by students is possible to be illustrated by a corresponding fragment from speech of one of heroes of video information in which this grammatical phenomenon appears. Nonverbal ways of the native speakers' dialogues, various gestures, and signs also can be illustrated by video information. For illustrative viewing, there are some algorithms of training technology. They differ in pre-viewing work. Figure 5a shows the algorithm for illustrative viewing.

Let us consider the block diagrams presented on Figure 5. The algorithm consists of 4 blocks. For example, students are offered to fix independently the certain phenomenon in the course of viewing, and then to pass to its discussion. For example, to fix, what sights have been shown during walk on a city. In another variant of algorithm the description of the phenomena and objects that they will see is offered to students, comments are given, and then the video information is shown. For example, sights are listed, their characteristics are given, photos and drawings are shown, the background is told, and then it is offered to look at all it in video information. The first kind of algorithm actually is a version of search viewing, but in this case we pay attention to illustrative function of viewing.

Fact-finding viewing is aimed at the reception of a general idea about a video information and its subjects. It is the process of viewing with the general coverage of the maintenance and concentration on understanding of the most essential. The minor, insignificant facts and unimportant details can be left. In this process synthesis prevails over the analysis. It assumes the ability to define a theme, to allocate the basic idea, to find the main facts from the text. As a result, students get skills of forecasting, allocation of semantic marks and support in the text, learn to guess value of keywords and to do without the words which meaning is not known to them. Fact-finding viewing is an indispensable component of studying and critical viewing and can precede them. Generation of oral and written statements based on video information can be result of viewing, for example, fact-finding viewing is carried out with concentration on the subsequent transfer of the video information basic maintenance in the form of a short oral or written statement-the resume, summaries etc.

When realizing a fact-finding viewing students' attention has to be attracted to video information as a whole without concentration on certain facts. The basic educational problem that faces students consists in finding out the basic information and problems as a result of viewing. The information processing is made consistently and involuntarily and results in construction of complex images. Figure $5 \mathrm{~b}$ shows the algorithm of foreign language training technology for fact-finding viewing of video information.

Studying viewing is connected to the extraction of the full information, to the concentration on full and exact understanding of all basic and minor facts, their mental processing and storing. At studying viewing the student assumes to reproduce or to use the received information subsequently in this or that form: to retell orally or in written form, to estimate, to make comments, to explain the information, in common to discuss the video information maintenance. This kind of viewing is considered to be the most difficult, and requires considerable efforts and time.

Studying viewing provides full and exact understanding of all video information as much as possible, and its critical processing. There are some variants of training technology algorithms based on studying viewing. Let us consider one of them presented in Figure 5c. This algorithm shows the complete technology of training including fact-finding and studying viewing consistently. The algorithm consists of four stages uniting 11 blocks. Each stage has the certain educational purposes and comes to the end with the control block. The control results define the possibility of transition to a following stage or returning to the previous one. 


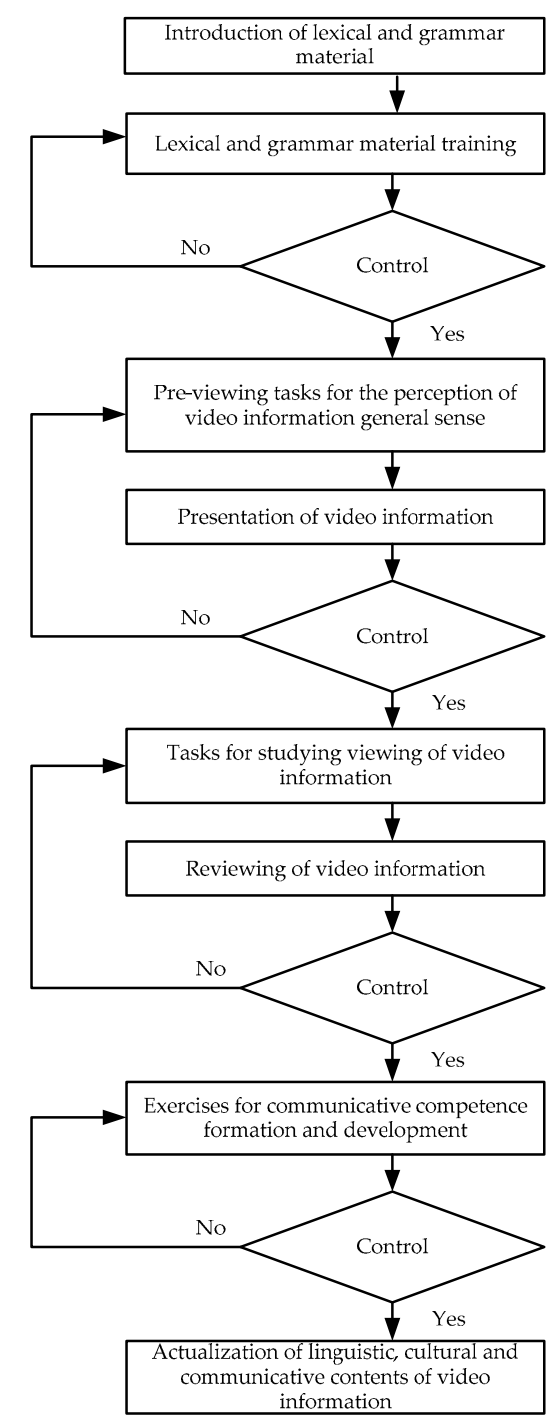

(c)

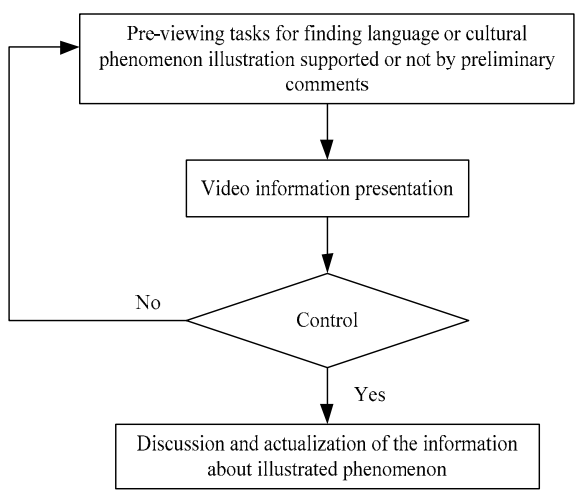

(a)

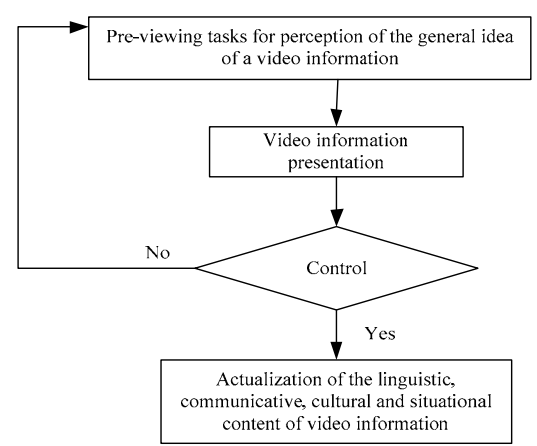

(b)

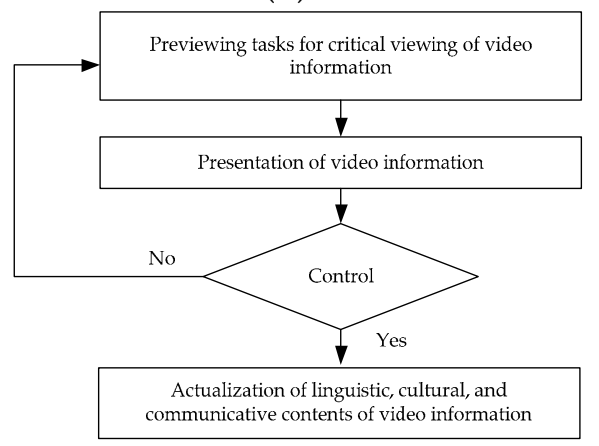

(d)

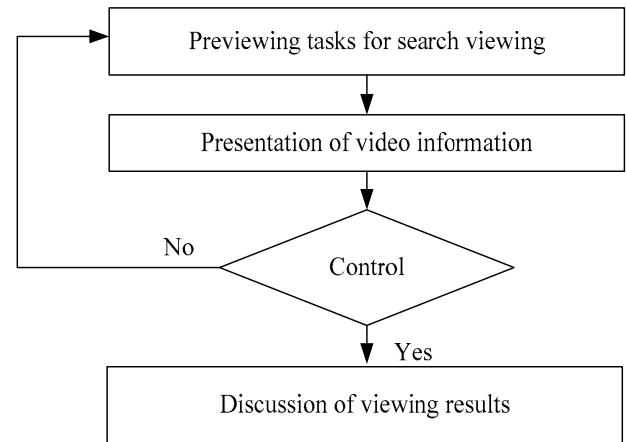

(e)

Figure 5. (a) Algorithm of foreign language training process based on video information (illustrative viewing); (b) Algorithm of foreign language training process based on video information (fact-finding viewing); (c) Algorithm of foreign language training process based on video information (studying viewing); (d) Algorithm of foreign language training process based on video information (critical viewing); (e) Algorithm of foreign language training process based on video information (search viewing). 
The purpose of the first stage is the language competence formation allowing to remove lexical and grammatical difficulties at primary viewing of video information. As it has been specified above, the language competence is considered to be a component of the communicative competence and defined as possession of lexical and grammatical knowledge and skills.

The first stage begins with introduction of a lexical and grammar material. Then training of lexical and grammatical material based on exercises follows. Work is organized with use of a special video guide and didactic materials prepared by the teacher. The first stage ends by the control block. It allows to define, whether transition to a following stage is possible. For level definition of the language competence level the method of tests is used at the first stage. The teacher carries out the analysis of the errors made by students, and returns to the block "Training of a lexical and grammatical material" based on the additional exercises offered by the teacher. Sufficient level of the language competence allows to pass to the following stage consisting of 3 blocks.

The purpose of the second stage is the understanding of the basic content of video information for the further transition to studying viewing. The second stage begins with the formulation of previewing tasks for revealing of understanding of the basic maintenance of video information. It is necessary to formulate a communicative problem for students: what is the purpose of viewing?

We pass to the following block- "Presentations of video information". The finishing block at the second stage is also the block of the control based on previewing tasks formulated at the beginning. At the second stage, the control has for an object the level of understanding of the video information general idea. At the beginning, students answer the questions put by the teacher before viewing. Then different tasks can be used.

If the control shows level of understanding to be less than sufficient, it is necessary to return to the block of previewing tasks, exercises, and then review video information again. If the control shows sufficient level of perception and understanding of the general sense of video information, we pass to the following stage of work.

The purpose of the third stage is formation of a situational basis for the further formation of the communicative competence. The maintenance of video information should become a situational basis, features of a plot, the characteristic of heroes etc. The third stage begins the block "Tasks for studying viewing". Tasks should aim students at the detailed perception of video information. The formulation of tasks is followed by the block of video information reviewing. This stage ends by the control block. The control purpose at this stage is to check the level of a situational basis for the communicative competence subsequent formation. The control at the end of the III stage allows to define the students' knowledge of the actual detailed information on the maintenance of a video information. It is very important because this knowledge becomes communications basis at the following stage. If the situational basis is insufficient, it is necessary to return to the block "Tasks for studying viewing of video information" and further to viewing. If the situational basis is sufficient, we pass to the fourth stage.

The purpose of the fourth stage is the formation of the communicative competence. This stage is aimed at development of students' productive speech. Various kinds of tasks and exercises for the communicative competence formation are offered. They are directed on development of students' abilities to interpret, make comments, and analyze the information and to reproduce it. This stage is based on tasks on commenting, discussion making, interpretations of the problems mentioned in a video information, problems without a support of verbal stimulus. Among these exercises the most interesting are: interviewing, discussion, "round tables", role-playing games, dramatization, statement of students' own problem questions on the problem mentioned in a video information (for the discussion organization), the statement of students' own opinion on a problem, etc. The imitating modeling is used at this stage, allowing to create various situations close to real ones as much as possible.

The fourth stage ends by the communicative competence control. Control is made by test methods and traditional ones. Results of control allow to define the communicative competence level. If the final 
tests results are insufficient, it is necessary to return to tasks. The communicative competence sufficient level means the end of pedagogical algorithm and beginning of the studied material actualization stage. Various kinds of the reflexing, allowing to comprehend, estimate, correct available professional and personal experience are used at all stages of work of algorithm.

There is another variant of algorithm for audiovisual technology realization. In this variant after presentation of a video information and understanding control there is a block of exercises for the communicative competence development without fact-finding viewing. The third variant of algorithm - without training of the entered lexical and grammatical material is used, too. The lexical and grammatical material has to be introduced, but its training and mastering control are not carried out. Previewing tasks for perception of the video information general sense are formulated.

There is the fourth variant of algorithm of studying viewing. It presents the sequence of operations at studying viewing without preliminary introduction and training lexical, grammatical and cultural material.

In the following variant of realization of training technology the block of lexical and grammar material introduction can be absent. After the first presentation, we have to check up the general sense understanding. In the second block, there is a detailed perception of video information preceded by viewing tasks formulation.

Critical viewing is aimed at the critical analysis, assuming an estimation of the video information maintenance and its correlation with the personal point of view, knowledge, with own life experience. The estimation is impossible without full and exact understanding of a video information, thus, critical viewing is based on studying viewing.

During viewing of this kind, the video information actually plays a role of a situational basis for the organization of the further discussion. The following sequence of actions presented on Figure $5 \mathrm{~d}$ is proposed. Tasks for critical perception are formulated, and then critical viewing is carried out. It is followed by the problems understanding control. In this way, we have a situational basis for discussion that follows.

Critical viewing is a version of illustrative viewing as the illustration of a problem that will be discussed is carried out. We define it as a separate kind of viewing to underline the critical relation to a material that is subject for viewing. It is an indispensable condition of the further discussion organization. Critical viewing promotes formation and development of the critical thinking which is considered to be very important for a personality development.

Search viewing is aimed at fast finding certain information in a video material (facts, characteristics, digital indicators, instructions, dates, proper names etc.). Students have to be informed that the video material contains the information needed. Extraction of the semantic information occurs automatically. Search viewing assumes the ability presence to be guided in logic and semantic structure of a video information, to choose from it the necessary information on a certain problem, to choose and unite the information of several video information on individual questions. Search viewing is focused on work with video information of cultural or special professional character. This kind of viewing is aimed at searching some special information. As it has already been marked above, search viewing is a version of illustrative viewing, as Figure 5e shows.

\subsection{Making Your Own Video}

The major assumption behind this paragraph is that the lens of the video camera creates a reality of its own and that people who control the camera have considerable power. This part is about letting students explore this area of camera control so that they feel this power, experiment, and create in their own way.

We see video as offering language students a subject area in which they are usually beginners. Via the medium of foreign language they start to learn what they can do, both individually and in a team, when offered a minimal task and a short time to fill with moving pictures. Foreign language then becomes the language of the creative process. The language is the instrument, which the students 
use in finding out about this extraordinary new world of restrictions and opportunities. An example may help: three students are given a space to work in, a camera, a travelling bag, and two chairs. Their task is to spend half an hour making a two-minute video about the two chairs and the bag. There are to be no flesh and blood actors in the video. The illusion of actors is created by the camera work. The students are free to shoot their video exactly as they like. The only stipulation made by the teacher is that the working language must be foreign language. The camera crew round off the exercise by showing their two-minute video to the class; they see and hear how their classmates react to what they have made.

The kind of camera use we are proposing here differs radically from the video work we have seen in some colleagues' classrooms, where the students prepare long stretches of language, the teacher videos them producing it, and then spends time going over their mistakes. In this sort of work the focus is largely on the language the students produce in front of the camera. The camera is being used as a passive recording device, not as a maker of reality. We are proposing that the students should control the interaction between the camera and the scene being portrayed. Much of the real language work will come in the process of discussing, brain storming, planning, videoing, reformulating, and trying out again. Language may well be produced on camera, but the main use of language is in the videoing process itself. At no point in the book do we propose that language produced in front of the camera should be used as text suitable for teacher-led correction sessions. When a small group of students presents the class with a video they have just made, the focus is naturally on the whole viewing experience not on the fragments of recorded inter-language that do not conform to the norms of standard language. There are other times and places for correction.

The object of attention in the activities is the exploration of the world of video and the way it relates to oneself and to others in the class. Again, an example may help: two people leave the group for half an hour to make a three-minute video in which one of them describes his or her own face while the other videos the features being described. The result is a word and picture evocation of self, which is subsequently shown to the whole class (Pisarenko and Krasnoshchekova 2016).

If you want students to practice descriptive language, this is an exploratory, personal, and real way of doing it. It is real in the sense that the speaker is relating to the image of himself or herself on the monitor as they are being videoed, to the presence of the camera person, and to the rest of the class who will see the video later. In this type of activity people are saying important things to themselves and each other via the camera.

\section{Results}

\subsection{Baseline Characteristics}

The average age in the intervention group was 18.0 years (range 17-21 years), comparable to the control group with 18.6 years (range 17-23 years). There were more males in the control group compared to the intervention group ( $92 \%$ vs. $88 \%$ ). For both groups, all residents had had their foreign language studies in Russia, but one for each group (educated in the Ukraine). See Table 1 for descriptive statistics.

Experimental research has been carried out in two groups of students: control and intervention. Both groups were studying foreign language. The period of studies, the quantity of students, the starting level of foreign language communicative competence, the program contents were identical. 
Table 1. Descriptive statistics of the Intervention and Control groups.

\begin{tabular}{ccc}
\hline & Intervention Group $(n=25)$ & Control Group $(n=24)$ \\
\hline $\begin{array}{c}\text { Average age (years) } \\
\text { Foreign language-English }\end{array}$ & 18.0 & 18.6 \\
\hline & 25 & 24 \\
\hline $\mathbf{6}$ & Years of foreign language studies \\
7 & 9 & 7 \\
8 & 6 & 5 \\
9 & 3 & 4 \\
$\mathbf{1 0}$ & 3 & 5 \\
& 4 & 3 \\
\hline The Russian Federation & Basic foreign language education \\
The Ukraine & 23 & 23 \\
\hline & 2 & 1 \\
\hline male & Gender & 88 \\
\hline
\end{tabular}

\subsection{Foreign Language Communicative Competence}

Indicator of the level of a foreign language proficiency is a certain level of formation of foreign language communicative competence. Foreign language communicative competence is a set of knowledge, abilities and skills that allow a student to organize an active communication and to provide an effective interaction with information in different spheres of life.

If we consider the formation and development of foreign language communicative competence of the student, it is necessary to speak about the following stages: (1) formation of the foreign language communicative competence; (2) its development; (3) perfection.

The given process should be presented in the form of a cycle, as it is impossible to imagine the formation of the foreign language communicative competence and its development separately taken. The students have a certain level of the foreign language communicative competence when they enter a high school. This competence has to be developed. In the education process, we develop the existing competences and we form new ones, for example, competence in some new grammar material. Nevertheless, offered stages cannot be considered as stages of educational process as they, in turn, mean certain sequence of educational actions.

For the communicative competence level estimation, we use calculation of knowledge acquisition factor of training material (Pisarenko 2015). Knowledge acquisition factor is considered to be a measure unit for a student's communicative competence level estimation. The maximum value of the knowledge acquisition factor is equal to 1 . The knowledge acquisition factor is defined as

$$
Q=\frac{m}{k}
$$

where $Q$ corresponds to knowledge acquisition factor; $m$ means the number of the right answers; $k$ is the number of possible answers.

\subsection{Knowledge Acquisition}

Basic course of a foreign language training in high school lasts two years. Before training, students perform a pre-test knowledge questionnaire that allows determining the level of foreign language communicative competence.

The groups were working with the identical tutorials and programs. The intervention groups were proposed to use audiovisual technologies in education process. The control groups have never used video materials in studies. The programs and topics were identical. The aim of the foreign 
language training was to form and to develop the foreign language communicative competence that includes different skills, abilities and knowledge of grammar, pronunciation, vocabulary, interpretation etc. In addition, it includes skills in reading, writing, audition and speaking.

At the end of the first and second years of study, students perform post-tests to determine the foreign language proficiency level. From the group of residents who had completed both the pre- and post-test knowledge questionnaire, the residents in the intervention groups $(n=25)$ scored on average 0.8125 for the post-test after the first year of studies; 0.8475 -after the second year of studies. The residents in the control group $(n=24)$ scored on average 0.615 for the post-test after the first year of studies; 0.62-after the second year of studies.

For convenience of data processing groups have been ranged according to years of formation. Table 2 reports a comparison among results of the analysis of knowledge acquisition factor for control and intervention groups for four years of training. The measurements have been based on complex tests composed by the author.

Table 2. Knowledge acquisition factor for control and intervention groups for three years of training.

\begin{tabular}{cccc}
\hline Year of Groups Formation & Group & $\begin{array}{c}\text { Average Factor of Mastering } \\
\text { of the First Year of Studies }\end{array}$ & $\begin{array}{c}\text { Average Factor of Mastering } \\
\text { of the Second Year of Studies }\end{array}$ \\
\hline $\mathbf{2 0 1 3 - 2 0 1 4}$ & Control & 0.62 & 0.63 \\
& Intervention & 0.78 & 0.81 \\
$\mathbf{2 0 1 4 - 2 0 1 5}$ & Control & 0.61 & 0.59 \\
& Intervention & 0.85 & 0.87 \\
$\mathbf{2 0 1 5 - 2 0 1 6}$ & Control & 0.63 & 0.64 \\
& Intervention & 0.83 & 0.86 \\
& Control & 0.60 & 0.62 \\
\hline
\end{tabular}

Results of knowledge acquisition factor in control and intervention groups at the end of the first and the second years of training are illustrated in Figures 6 and 7.

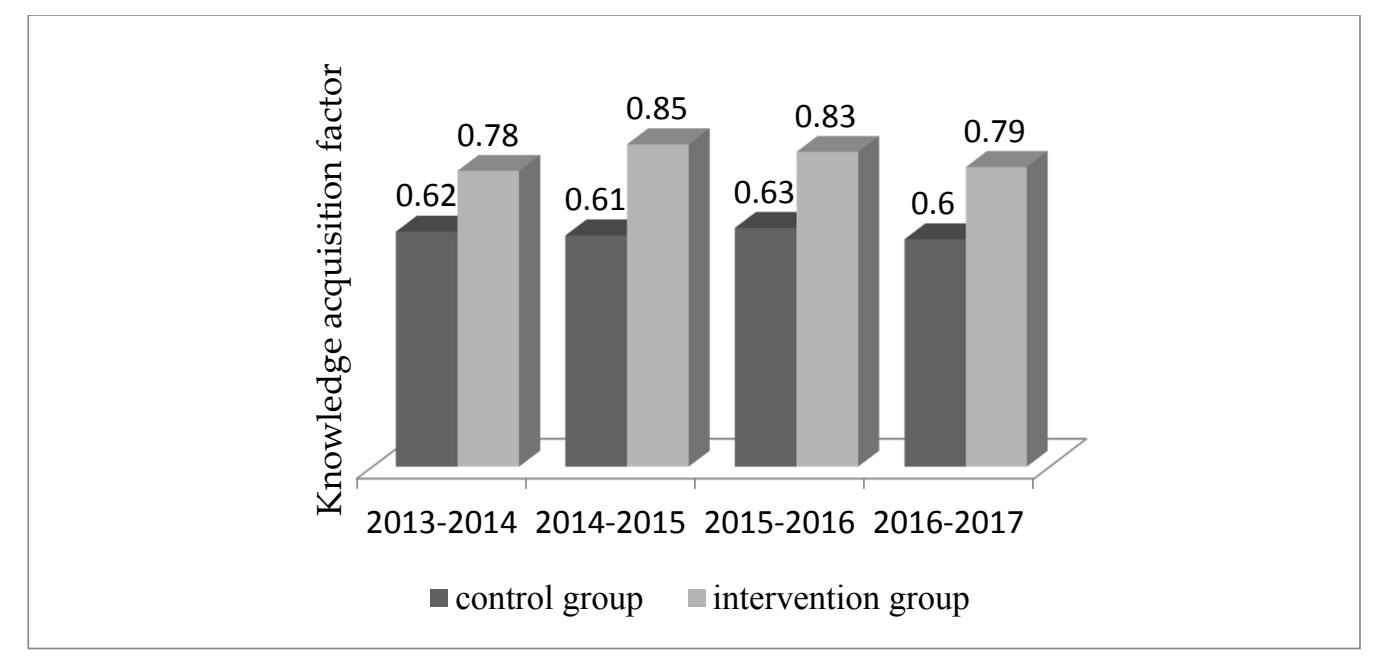

Figure 6. Diagram of dynamics of knowledge acquisition factor for control and intervention groups for the first year of studies. 


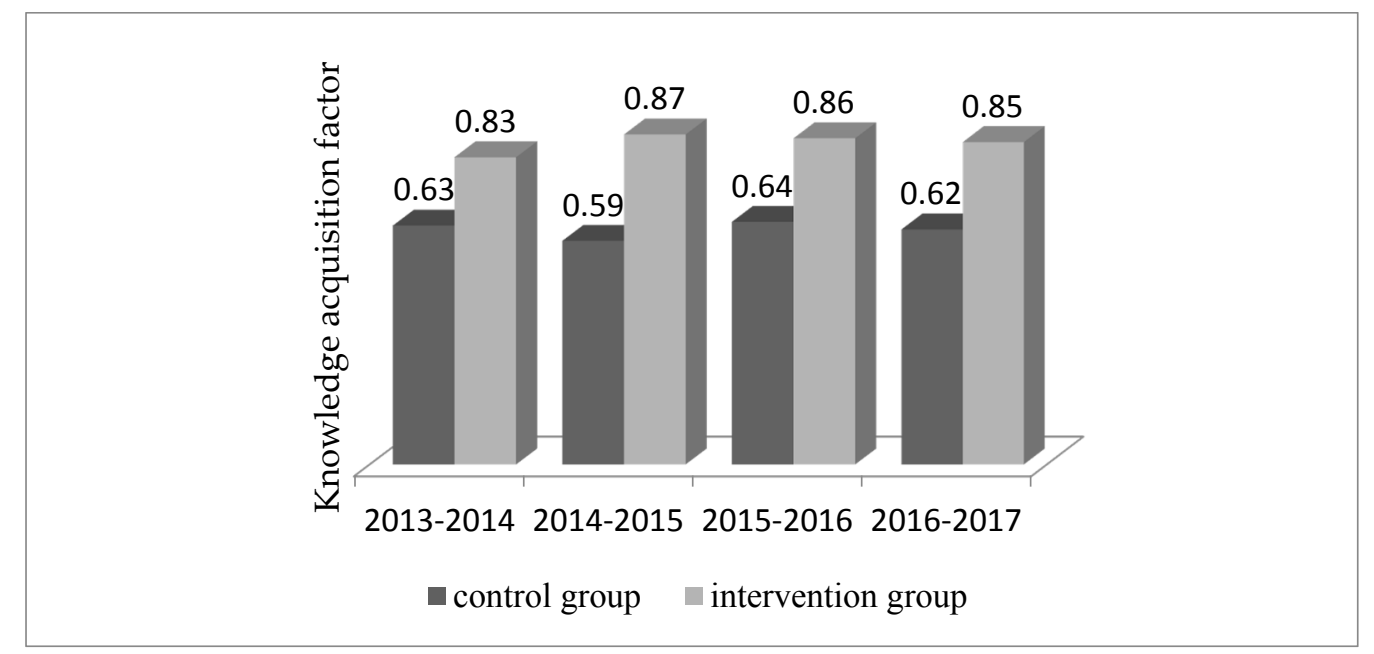

Figure 7. Diagram of dynamics of knowledge acquisition factor for control and intervention groups for the second year of studies.

The analysis of the data of training results allows to make the following conclusions:

According to the final language tests results the knowledge acquisition factor after 2 years of training testifies that the offered program, both in control, and in intervention groups is acquired.

The communicative competence level of intervention groups is higher than in control groups. Average knowledge acquisition factor is equal to $0.78-0.85$ in intervention groups, to $0.61-0.63$ in control groups. At the end of the first year of training knowledge acquisition factor is higher in intervention groups, than in control on the average on 0.2 ; at the end of the II year of training-on 0.23 .

Use of audiovisual technologies in foreign language training leads to quantitative increase knowledge acquisition factor that is expressed in qualitative increase of level of students' communicative competence in foreign language.

Above descriptions show that the methods of exploiting video information in foreign language training could vary greatly in many aspects. Moreover, some techniques can be easily integrated into other methods and forms of education process.

Variants of pedagogical algorithms of technology realization are applicable for work with any kind of video information taking into account possibility of entering of some changes connected with depth of perception of a material. From the point of view of sequence of actions, they consider psychological features of video information perception, and methodical features of the organization of foreign language educational process. The application of the developed algorithms will promote the most rational organization of educational process based on the maximum use of all advantages of audio-visual synthesis and taking into account all stages of communicative competence formation. Training process will be even more effective if in realization of audiovisual technologies of training style characteristics of students about which it was told above are considered.

\section{Discussion}

In this study, various algorithms of audiovisual technologies realization for foreign language training were designed using the technological and system approaches. We then set out to investigate if this educational intervention resulted in significant foreign language knowledge acquisition and test if the audiovisual technology was an effective foreign language teaching method for this purpose. The results of this study indicate that the audiovisual technology was perceived to be both effective in increasing residents' knowledge of the foreign language as well as an effective educational tool and means of student's personality development. Knowledge acquisition was significantly higher in the intervention group, compared to the control group. In addition, the residents valued the training 
technology highly. Central to this were the notable levels of interaction during the foreign language training and the direct application of content to the language practice setting. The qualitative data also suggest that the audiovisual technology is effective in teaching foreign language.

A video course represents a single whole including the tasks and educational problems, created by authors of video course. The teacher has to follow the structure of educational process offered by video course authors. Video course is a developed technology aimed at realization of certain goals.

Use of video films promotes realization of the requirement of a communicative technique-to present the process of language mastering by comprehension of live culture speaking another language; an individualization of training and development of motivation of speech activity of students (Pisarenko 2015; Sanders 2016). Another advantage of video films is their emotional influence on students. Therefore, the special attention should be given to the process of formation of the personal relation to the materials used in training process (Fails 1988). It is the main objective of the personality focused training paradigm. Successful achievement of this purpose is possible firstly at regular display of video films, and secondly, at their methodically organized demonstration. The use of video films helps to develop various kinds of student's activity, and also their attention and memory. At video material viewing, there is an atmosphere of joint informative activity that promotes the increasing of attention concentration (Stempleski 1989). Use of various channels of the information perception influences positively durability of storing of a regional geographic and language material (Banner and Rayner 2000). Psychological features of video films influence on students promote an intensification of educational process and create favorable conditions for the communicative competence formation. The teacher defines, whether it is necessary to include a video film consistently in educational process, or to use separate episodes taking into account conformity of subjects of a video film to a basic word stock and the communicative situations included in the foreign language program for a concrete grade level (Daniels 1994). The information quantity and character should correspond to quantity and quality of the information that the student studying a foreign language is capable to acquire at a given time.

Efficiency of use of a video film in educational process depends on exact definition of its position in training system, on coordination of educational possibilities of a video film with training problems, on rationality of organization of work, and on functional features of a video film (Pisarenko and Krasnoshchekova 2016; Stover 1978).

There are the following functional features of a video film used in educational process:

Informative and training function-the student is involved in the film's subject line and in the process of information transfer simultaneously; this information will be used in the course of training;

Illustrative and evident function-video film shows a subject line in the art form;

Organizational and operational-it is realized in concentration and the subsequent management of students' attention by means of a subject line and art features of its embodiment;

Educational-it is embodied in realization of certain ideas in the art form and statement of problems that the student will discuss further;

Integrating - in the course of viewing there is a process of integration of various kinds of perceptions, and also various aspects of language - phonetic, lexical etc. (Murphy 2011).

In general, there are multiple advantages to the audiovisual technologies. First, the audiovisual technology caters to the educational needs of the individual student learning a foreign language through high levels of interaction and collaboration (Sanders 2016; Tight 2010). This was supported by evidence from the students' interviews. Secondly, it allows students select their preferred foreign language learning styles and control both time and pace of language learning (Murphy 2011; Chavez et al. 2003). Thirdly, audiovisual technologies provide opportunities of nonlinear organization of the foreign language learning process (Pisarenko and Arsaliev 2016). It does not take only one direction; it has many ways of language learning providing opportunities for students to choose their individual educational route in mastering foreign language communicative competence and the timing of its passing (Pisarenko and Bondarev 2016). Fourth, audiovisual technology provides 
the unity of teaching, learning and development. The education process is realized as a complex of interactions of all the participants focused on the development of the student individuality, his autonomy. Fifth, a combination of individual, pair and group classroom work and students extracurricular activities, sometimes the domination of self-study work over training by the teacher (Zablotskaya 2014). When learning a foreign language students receive a list of additional literature and audio/video materials beforehand from which they can source their information concerning the content of a subject being studied. Guided with triggering, practical questions, students learn the basic concepts ahead of class so that face to face class time can be devoted to 'higher-order learning activities' such as discussions and practical scenarios and thereby ensuring and optimizing productive character of educational student-teacher and student-student communication activities (Sanders 2016; Pisarenko and Krasnoshchekova 2016). In addition, audiovisual technologies allow demonstrating all aspects of a foreign language: phonetics, vocabulary, grammar, geography, form and characteristics of communication between native speakers of the language, customs and traditions of the people etc. (Arsaliev 2016). Lastly, and most importantly, audiovisual technologies optimize the perception of the material as they use two information perception channels - audial and visual. A person always has a leading modality of perception, which allows perceiving better than others do. Audiovisual technologies allow you to develop all channels of perception and improving cognitive activity of students (Tight 2010).

There are also a few disadvantages to the audiovisual technologies in training foreign language. First, the development and implementation of audiovisual technology in teaching foreign language is time-consuming for the teacher. The preparation involves a time investment. It should be noted that the design and development of the audiovisual technology initially takes a considerable amount of time and effort. The teacher needs to develop the technology, to adapt it to the specific conditions of the educational process and create conditions for its successful implementation, and to analyze the results of its implementation (Pisarenko 2015). Second, the successful implementation of audiovisual technology fully depends on the availability and functioning of technical training tools. Without the appropriate equipment implementation, this type of technology is not possible. This means that the teacher must have the appropriate technical support of the educational process (Brečka and Bitterová 2012). Third, working with videos is a more complex activity, since foreign language is perceived as a complex phenomenon. It is the simultaneous perception of the phonetic, grammatical, lexical, cultural and other types of materials. It is quite difficult and may cause additional challenges for students. Removing these constraints will require additional time.

Regarding the preparatory materials, handouts, and exercises, there are three potential drawbacks. First, there is the risk of using technology for the sake of technology (Mitchell 1989, 1997). This concerns the use of video materials. Contrary to popular thought, the driving factor behind the success of audiovisual technologies is not based on the availability and use of pre-recorded video materials. Rather, the role of technological tools lies in supporting a pedagogical teaching strategy (Corbalan et al. 2011). Lastly, the implementation of audiovisual technology requires the development of a large number of different exercises to work with different aspects of language and kinds of speech activity. Exercises should be structured and selected in strict accordance with the logic of the educational process. The content of educational material must correspond to the interests of students.

Despite the interesting findings in this study, there were a few challenges that we faced. The first the work was carried out in a technical university. Foreign language is not a profile discipline in a technical university; it is a part of the Humanities in high school. The technical high school students have some difficulty learning a foreign language. Another problem is a small number of hours for a foreign language training in a technical University. Contact hours are not always enough to achieve your goals in learning a foreign language. Unfortunately, the students' skills of individual work in foreign language training are developed insufficiently. The regular knowledge acquisition factor decrease in intervention group in 2014-2015, 2015-2016, and 2016-2017 can be explained by systematic low entry-level knowledge in a foreign language with which the students begin to study. 
Furthermore, the difference in foreign language knowledge acquisition between the intervention and control groups could be attributed to the different amount of exposure to the content, and not necessarily the audiovisual technology itself.

Even though some residents would have preferred the training to have been longer or spread out across multiple days, residents' perception of audiovisual materials was very high, and this was reflected in both the group evaluation and during the interviews. While we acknowledge that this study is preliminary in nature and the results need to be replicated in future studies, we believe that the audiovisual technologies could have a lasting impact on residents' performance in foreign language. This is supported by the call for more studies with a focus on how to increase the effectiveness of foreign language training. Other options would be to include specialty-oriented materials in foreign language training. Lastly, we would highly recommend selecting technical specialties individually for participation, to further increase the demands to the initial level of language competence for a student entering a technical high school. With this study, we believe that the first careful steps toward an effective use of audiovisual technologies for foreign language training in technical high school have been made. We believe the education technology is essential in this process and should play a leading role in education.

\section{Conclusions}

A central idea of this paper is to bring the common sense of humanistic thinking to the area of foreign language teaching based on video work in accordance with some simple principles:

- the learner is considered to be a center of education process as actor, doer, creator, and interpreter of video; all education process is organized for learner and is aimed at formation and development of foreign language communicative competence;

- the teacher offers the learner video resources of different types in various forms and stages; they are selected by teacher and processed for being used in education process;

- the operational part of audiovisual technologies is realized by pedagogical algorithms; their selection is defined by purposes of education process;

- $\quad$ since learners (and teachers) are very different from one another, they need to be provided with a wide range of activities and stimuli;

- all text is produced by the students - when viewing they produce their own very particular, internal version of what is on the screen; when videoing they make all the decisions both behind and in front of the lens;

- $\quad$ even course book material can have life breathed into it by letting the students take it over and re-fashion it in their own special way;

- experimental research has shown the effectiveness of audiovisual technologies use in education process.

In conclusion, our study is probably a first example of the audiovisual technologies application as a system to teach foreign language in high school. Compared to the control group who were exposed to a passive learning process (i.e., study materials only), the amount of knowledge acquired was shown to be significantly higher in the residents who participated in the active learning based on audiovisual technologies. The residents were also satisfied with both the content and format of the training techniques. Overall, this study demonstrates that the audiovisual technologies can contribute to the effective teaching of a foreign language, as part of a high school base humanitarian education program.

We briefly discussed the problem of using video in training process. Successively, we focused our attention on different types and forms of video information: video films, video information and self-made video. Moreover, this study allowed us to underline the main features of different types of video used in foreign language training process. The experience of teaching with video meets expectations and clearly confirms the application and the use of video in education. 
Our goal for the future is greater use and further development of audiovisual technologies in foreign language training. Further development of the humanistic environment and its effective co-existence with existing traditional tutorials requires different approaches and collaboration. Our past experiences and current trends in audiovisual technologies clearly determine and will determine our future directions and activities in this area. The current situation in foreign language teaching should prompt us to conduct more researches on audiovisual technologies, developing new algorithms and tasks to increase the effectiveness of foreign language teaching.

Conflicts of Interest: The author declares no conflict of interest.

\section{References}

Alava, Séraphin, and Etévé Christiane. 1999. Note synthèse. Revue Française de Pédagogie 127: 119-64. [CrossRef] Andrade, Rafael de Castro, and Carla Galvão Spinillo. 2013. Interactive and Animated Journalistic Infographics: Analytic Study about Infographics Health. Paper presented at 6th Information Design International Conference, Recife, Brazil, September 10-13. [CrossRef]

Arsaliev, Shavadi. 2015. New information technologies in ethnopedagogical process. Paper presented at 9th International Conference on Application of Information and Communication Technologies (AICT), Rostov-on-Don, Russia, October 14-16. [CrossRef]

Arsaliev, Shavadi. 2016. Ethnopedagogical Technologies: Best Approaches and Practices. Recent Patents on Computer Science 9: 173-84. [CrossRef]

Babansky, Iurij Konstantinovich. 1973. Optimization of the Teaching Process. Russian Education E Society 15: 3-18. [CrossRef]

Babansky, Yurij Konstantinovich. 1987. The Modernization of Educational Research Methods in the USSR. Prospects 17: 185-98. [CrossRef]

Baguley, David, Andersson Gerhard, McFerran Don, and Laurence McKenna. 2013. Cognitive Behaviour Therapy. In Tinnitus: A Multidisciplinary Approach, 2nd ed. West Sussex: John Wiley \& Sons, Ltd.

Banner, Gloria, and Steve Rayner. 2000. Learning Language and Learning Style: Principles, Process and Practice. The Language Learning Journal 21: 37-44. [CrossRef]

Bégin, C. 2008. Les stratégies d'apprentissage : Un cadre de référence simplifié. Revue Des Sciences de L'éducation 34: 47. [CrossRef]

Brečka, Peter, and Miriam Bitterová. 2012. Technical Education Support in Pre-Primary Education by Interactive Teaching Systems. Acta Technologica Dubnicae. [CrossRef]

Carterette, Edward C., and Morton P. Friedman. 1978. FOREWORD. In Handbook of Perception. Amsterdam: Elsevier Inc.

Chavez, Alicia Fedelina, Florence Guido-DiBrito, and Sherry L. Mallory. 2003. Learning to Value the 'Other': A Framework of Individual Diversity Development. Journal of College Student Development 44: 453-69. [CrossRef]

Corbalan, Montserrat, Emiliano Aldabas, Pou Josep, Zaragoza Jordi, Igual Raul, and Inmaculada Plaza. 2011. An Approach on How to Use Audiovisual Resources at Engineering Higher Education. Paper presented at Conference Promotion and Innovation with New Technologies in Engineering Education (FINTDI 2011), Teruel, Spain, May 5-6. [CrossRef]

Daniels, Shirley. 1994. The Learning Organization. Work Study 43: 5-6. [CrossRef]

Deetman, Wilem Joost. 1989. New Technologies in Higher Education: Chaos or Progress? In Higher Education and New Technologies. Amsterdam: Elsevier, pp. 1-4.

Fails, Eleanor V. 1988. Teaching Sociological Theory through Video: The Development of an Experimental Strategy. Teaching Sociology 16: 256. [CrossRef]

Friedrich, Janette. 2001. Philosophie, psychologie et pédagogie : Un ménage à trois. In Le Pari des Sciences de L'éducation. Paris: De Boeck Superieur, p. 57.

Kibalchenko, Irina Alexandrovna, and Eksakusto Tatiana Valentinovna. 2016. Descriptors of Successful Entrepreneurial Activity. Socio-Humanitarian Research and Technology 5: 41-6. [CrossRef] 
Kibalchenko, Irina Alexandrovna, and Alla Igorevna Zabalueva. 2017. Educational-Cognitive Competence as a Factor of Formation of Professional Competence of Students. Modern Problems of Science and Education. Available online: https://www.science-education.ru/ru/article/view?id=26243 (accessed on 16 October 2017). [CrossRef]

Kibalchenko, Irina Alexandrovna, Tatiana Valentinovna Eksakusto, and Vitaly Sergeevich Kompaniets. 2015. Personality Profiles of Young People-Potential Entrepreneurs. Mediterranean Journal of Social Sciences. [CrossRef]

Kitto, Kathleen L., and Sylvester Bernard. 2002. A Multidisciplinary Approach to Teaching Ethical Considerations in Engineering Technology. Paper presented at 32nd Annual Frontiers in Education, Boston, MA, USA, November 6-9. [CrossRef]

Kuhn, T. S. 1996. The Structure of Scientific Revolutions. Chicago: University of Chicago Press.

Mitchell, Jeff. 1989. Video: Multifaceted tool or window on passivity. Educational Technology Research and Development 37: 97-8. [CrossRef]

Mitchell, P. David. 1997. The impact of educational technology: a radical reappraisal of research methods. Research in Learning Technology. [CrossRef]

Murphy, Kevin R. 2011. Individual Differences Can Both Facilitate and Limit Individual Development. Individual Differences and Development in Organisations (n.d.). Oxford Handbooks Online, 53-72. [CrossRef]

Parker, Sue T. 1979. Mind in Society: The Development of Higher Psychological Processes. L. S. Vygotsky. American Anthropologist 81: 956-57. [CrossRef]

Pisarenko, Veronika. 2015. Informational and Technological Support of Foreign Language Training in High School. Paper presented at 9th International Conference on Application of Information and Communication Technologies (AICT), Rostov-on-Don, Russia, October 14-16.

Pisarenko, Veronika, and Shavadi Arsaliev. 2016. Audiovisual technologies for foreign laguages teaching. Paper presented at IEEE 10th International Conference on Application of Information and Communication Technologies (AICT), Baku, Azerbajdgan, October 10-14.

Pisarenko, Veronika, and Maxim Bondarev. 2016. Infographics Use in Teaching Foreign Languages for Specific Purposes. Recent Patents on Computer Science 9: 124-32. [CrossRef]

Pisarenko, Veronika, and Galina Krasnoshchekova. 2016. Video in Teaching. Paper presented at IEEE 10th International Conference on Application of Information and Communication Technologies (AICT), Baku, Azerbajdgan, October 10-14. [CrossRef]

Rieber, Robert W., and David K. Robinson. 2004. The Function of Signs in the Development of Higher Mental Processes. In The Essential Vygotsky. New York: Springer, pp. 539-50.

Sanders, Christina. 2016. Teaching and Collaborating via Video Conference. Paper presented at Innovations in Teaching \& Learning Conference, George Mason University, the USA, July 15. [CrossRef]

Soriano, Fernando I. 1995. SAGE Human Service Guide 68: Conducting Needs Assessments: A Multidisciplinary Approach. Thousand Oaks: SAGE Publications Ltd.

Stempleski, Susan. 1989. Teaching English with Video. System 17: 109. [CrossRef]

Stepin, Vyacheslav Semionovitch. 2007. Scientific Knowledge as Value of Modern Civilisation. In Technological and Environmental Policy. Glashütte: Nomos, pp. 19-40.

Stepin, Vyacheslav Semionovitch. 2008. Types of Systems and Types of Scientific Rationality. SATS 9. [CrossRef]

Stepin, Vyacheslav Semionovitch. 2009. Scientific Knowledge and Values of Technogenic Civilisation. In The Social Integration of Science. Glashütte: Nomos, pp. 35-68.

Stover, William J. 1978. Student Video Stimulus and Changing Images of the Soviet Union: An Experimental Pilot Study of Video in Teaching International Relations. Teaching Political Science 5: 333-42. [CrossRef]

Tight, Daniel G. 2010. Perceptual Learning Style Matching and L2 Vocabulary Acquisition. Language Learning 60: 792-833. [CrossRef]

Vernadsky, V. I. 1998. The Biosphere. New York, NY, USA: Springer. [CrossRef]

Vygotsky, Lev Semenovich. 1977. The Development of Higher Psychological Functions. Russian Social Science Review 18: 38-51. [CrossRef]

Vygotsky, Lev, Cole Michael, John-Steiner Vera, Scribner Sylvia, and Souberman Ellen. 1979. Mind in Society. The Development of Higher Psychological Processes. The American Journal of Psychology 92: 166. [CrossRef]

Wolfs, José-Luis. 2007. Méthodes de Travail et Stratégies D'apprentissage. Paris: De Boeck Supérieur. 
Zablotskaya, Oksana. 2014. Developing French for Specific Purposes Self-Study Support Materials for Mixed-Speciality Student Groups. Paper presented at SGEM 2014 Scientific SubConference on Psychology and Psychiatry, Sociology and Healthcare, Education, Bulgaria, September 1, 2014. [CrossRef]

Zankov, Leonid Vladimirovich. 1963. The Didactic Foundations of Teaching (Submitted for Discussion). Russian Education E Society 5: 3-12. [CrossRef]

Zankov, Leonid Vladimirovich. 1964. Convincing Experience. Russian Education E Society 6: 3-6. [CrossRef] Zaporozhets, Alexandr, and David Elkonin. 1973. Dialectics and Development: Soviet Preschool Psychology. Human Development 16: 243-47. [CrossRef] 